\title{
La iluminación de Macabea: el fracaso del narrador en La hora de la estrella, de Clarice Lispector.
}

\begin{abstract}
Resumen
Este ensayo analiza la problemática presente en la narrativa de Clarice Lispector, específicamente en su novela La hora de la estrella (1977), respecto de los modos de hacer ficción y de organizar las instancias narrativas en una historia. El autor pretende mostrar cómo en La hora de la estrella se articulan mecanismos que desestabilizan la norma tradicional de construir un relato, mostrando, en este caso, los límites que la voz narrativa padece en su deber de idear y exponer lo que constituye el argumento de la novela, así como el surgimiento de lo que se puede denominar como una voz alternativa de enunciación, esto dentro de una dinámica metaficcional. El ensayo, por lo tanto, también indaga la presencia y la disposición de ciertos obstáculos que, a modo de amenazas, ponen en crisis la autoridad de la narración y destruyen el orden establecido entre quien subordina y quienes son subordinados dentro del texto.
\end{abstract}

Palabras claves

Clarice Lispector, metaficción, narrador, novela, escritura.

\begin{abstract}
This essay analyzes the problems in Clarice Lispector's narrative, specifically in her novel The Hour of the Star (1977), concerning the ways of writing fiction and the organization of the narrative instances in a story. The author aims to show how The Hour of the Star articulates mechanisms that disrupt the traditional norm of constructing a story, showing, in this case, the limits that the narrative voice suffers in its duty to ideate and expound what constitutes the plot of the novel, as well as the emergence of what can be termed as an alternative voice of enunciation, this within a metafictional dynamic. The essay, therefore, also investigates the presence and disposal of certain obstacles that, like threats, throw into crisis the narrative authority and destroy the stablishment among those who subordinate and those who are subordinated within the text.
\end{abstract}


En 1977, durante una entrevista concedida a un programa de televisión brasileño, Clarice Lispector relataba, en respuesta a una pregunta acerca de la complejidad de sus libros, un episodio en el cual un profesor universitario se había tomado la tarea de localizarla y presentarse un día cualquiera en su apartamento para decirle que, tras haber leído en numerosas ocasiones La Pasión según G.H., su famosa novela, no conseguía entender sobre qué se trataba el libro. Al día siguiente, una joven de diecisiete años llevaba a cabo la misma acción, pero esta vez para confesarle a la escritora que La Pasión según G.H. era la mejor novela que había leído en su vida. En la entrevista televisiva, la autora remató su respuesta afirmando que el único motivo para que esto sucediera era asumir el acto de entender no como un hecho relacionado con la inteligencia, si no con un sentimiento de contacto distinto.

En esta misma entrevista, en parte obligada por la insistencia del reportero, Clarice Lispector también alcanzó a dar algunos detalles sobre un nuevo trabajo que acababa de finalizar: una historia identificada con trece nombres, con trece títulos, y protagonizada por una heroína marginal cuyo nombre, en ese momento, se negó a revelar.

Algunos meses más tarde, el texto citado parcialmente por Clarice Lispector en dicho reportaje televisivo aparecería bajo el título de $A$ hora da estrela [más tarde traducido al castellano como La hora de la estrella]. Este título se hallaba en la primera página, seguido de una lista que reunía otros doce nombres desplegados ante la mirada de los lectores a manera de epígrafes o de nombres que, como piezas intercambiables, podían de uno u otro modo sustituir al título principal de la novela. Dicho aspecto debería brindar alguna suerte de pista sobre las peculiaridades alrededor de las cuales gira la totalidad de la historia, pues $L a$ hora de la estrella establece condiciones que, de entrada, llevan a cuestionar no solo la caracterización tradicional de la novela como género literario, sino también su naturaleza ficticia. 
CATEDRAL TOMADA: Revista de crítica literaria latinoamericana / Journal of Latin American Literary Criticism La iluminación de Macabea: el frac aso del narrador en La hora de la estrel la, de Clarice Lispector.

El presente ensayo pretende utilizar este último aspecto, el de la ficción, para desarrollar algunas observaciones que pueden apreciarse al leer el texto mencionado, a saber, la presencia del elemento metaficcional a lo largo del relato escrito por Lispector, y la visión que en la novela se tiene de la escritura como un proceso ordenador y consciente. De este modo, es posible afirmar que la totalidad de este análisis se sustenta en dos hechos presentes en la novela: el uso de capas o niveles narrativos para contar la historia de Macabea, la protagonista, y la forma en la que estos niveles van develando poco a poco las limitaciones que el narrador principal del texto tiene en tanto observador objetivo respecto del resto de los personajes que él manipula. Parte de la argumentación mostrará cómo, de hecho, estos personajes se oponen en sus caracterizaciones a la mirada que dicho narrador desea tener sobre lo que cuenta.

Esta diferencia también arroja la categorización central del análisis, es decir, la distinción que desde el inicio se establece entre un pensamiento razonado, el del narrador, y un pensamiento irracional, el de los personajes. El propósito del ensayo es, por tanto, mostrar cómo mediante el uso de la metaficción, La hora de la estrella cuestiona la naturaleza de los narradores literarios en tanto organizadores totales de la historia, al tiempo que pone en tela de duda la potestad objetiva de su voz frente a otro tipo de conocimiento vivencial: el de los personajes.

Con el fin de desarrollar de forma adecuada cada uno de estos puntos, se procederá a realizar algunas observaciones acerca de la narrativa de Clarice Lispector, así como acerca de la metaficción presente en la novela $y$, principalmente, a la oposición ya mencionada entre los lugares que ocupan los personajes y el narrador dentro de la historia. 


\section{Límites}

La narrativa escrita por de Clarice Lispector parece ser incontenible a tal punto que, con frecuencia, sus historias se rebasan a sí mismas y van más allá del propio lenguaje con el cual han sido escritas y enunciadas. Esto posiblemente sea el producto de la unión entre formas de contar que, en principio, resultan totalmente apartadas entre sí. La crítica misma reconoce en su obra a una de las voces más extrañas e inquietantes de la literatura latinoamericana escrita a lo largo del siglo XX.

Sobre su propuesta [o propuestas], estudios como el llevado a cabo por Lucia Helena sostienen la imposibilidad de ubicar a la escritora brasileña dentro de un determinado marco historiográfico, motivo por el cual se acostumbra agruparla junto con otros autores igualmente complejos:

[...] a obra de [Guimarães] Rosa, [Autran] Dourado, e [Clarice] Lispector se toma avessa à reprodução das já clássicas estratégias do naturalismo e do realismo. Seus textos, por outro lado, também se afastam da estética do desvio formalista, ou «da bofetada no gosto do público» que caracterizara o primeiro modernismo. (Helena 1165)

Como se puede observar, hay una clara tensión de valores y acercamientos en la obra de Clarice Lispector que repele cualquier utilización exclusiva de una estrategia. De acuerdo con esto, la obra de la brasileña se halla atravesada, al menos, por dos principios básicos que [de]forman su estilo sin llegar a definirlo de manera completa: el distanciamiento de la verosimilitud, representado en las ideas realistas y heredadas del naturalismo, y una resistencia frente al uso de actitudes formales que ponen a prueba, por medio del desvío, la estructura paradigmática del discurso narrativo. 
CATEDRAL TOMADA: Revista de crítica literaria latinoamericana / Journal of Latin American Literary Criticism La iluminación de Macabea: el frac aso del narrador en La hora de la estrel la, de Clarice Lispector.

Asimismo, es común toparse con afirmaciones que recalcan el desdoblamiento presente en muchas de las historias y la estética de Clarice Lispector y que son mayormente vistas como esfuerzos por relatar aspectos poco explorados por la tradición tanto literaria como ideológica. Dicha exploración también ha sido abordada al margen de La hora de la estrella, en este caso, para señalar cómo la novela incluye discursos opuestos o desconectados. Bernardita Llanos lo explica de esta forma en su estudio:

La hibridez y el camuflaje en A hora da estrela construyen dos relatos: un metarrelato hecho por el escritor, narrador y personaje Rodrigo S.M. sobre la creación literaria y sus desafíos, y otro sobre Macabea, la inmigrante marginal de Alagoas recién llegada a Río de Janeiro y creada por Rodrigo [...] Lispector hace una crítica de la complicidad de los intelectuales y escritores con los problemas sociales existentes por su distanciamiento y posición privilegiada. (Llanos 272)

La postura desarrollada por Llanos evidencia un acercamiento a la narrativa de Clarice Lispector claramente atravesado por lo social; no obstante, también apoya la idea antes explicada sobre la presencia de realidades separadas que entran en juego en las historias creadas por la autora. En principio, es posible argumentar que la inclusión de ambientes alternos a lo hegemónico también se da con la intensión de reivindicar a los otros y ejercer alguna presión o duda sobre lo que se da por sentado, lo cual permite centrarse aún más en la novela en estudio y, en este caso, en los elementos de análisis citados al inicio.

Así, la indagación de un tópico como la marginalidad parece servir de excusa a la autora para colocar sobre el pedestal la figura de quienes no pertenecen al centro letrado/académico en el cual Llanos coloca a los intelectuales brasileños. De hecho, se puede ver cómo el epitome de dicha esfera intelectual vendría a ser el personaje de Rodrigo S.M., cuya presencia se encuentra situada en un lugar superior al resto de las voces en el texto. La crítica a las estructuras 
hegemónicas se hace manifiesta en la duda o la incertidumbre que rodea a este personaje en el relato, quien a regañadientes, tiene la responsabilidad de encausar la vida de otro personaje: la marginada. Tampoco resulta gratuito darse cuenta de que, conforme el argumento avanza, Rodrigo va perdiendo poco a poco la supuesta potestad de la que goza frente al resto de los actantes, ya que, aunque ellos no se apoderan totalmente de la narración, parecen rebelarse y violentar los límites que la voz narrativa ha ido colocando sobre la página.

Uno de los espacios más explorados en la literatura de Lispector es precisamente el uso de la metaficción como recurso para disolver cualquier límite que contenga a los elementos de la historia, ya sean lugares, personajes, acciones, o autores. En este sentido, es llamativo el hecho de que Llanos mencione a Rodrigo S.M., el narrador/creador, como un personaje más de la novela; esto podría servir como ejemplo para ilustrar la dificultad que el texto de Lispector presenta a momento de definir de manera terminante los roles que las voces participantes poseen. En un juego muy cercano a las aventuras quijotescas, la clasificación citada por Llanos establece un vaivén entre el discurso escrito que forma parte de nivel argumental de la novela, y el discurso escribidor que "controla" lo que sucede en dicho nivel.

Un esquema de esta clase se completaría si los personajes narrados por Rodrigo S.M. alcanzaran a referirse a él en algún momento de la novela. Clarice Lispector parece ignorar dicho aspecto de forma deliberada, pues, como se explicará más adelante, el giro con el que la narración culmina puede no establecer un diálogo directo entre el creador y los creados, sin embargo, en la ausencia de dicho dialogo parece esconderse la clave con la cual la autora destruye la forma tradicional de novelar y ficcionalizar determinados acontecimientos.

La metaficción es, de hecho, un rasgo característico de la estética posmoderna producida a partir del siglo $\mathrm{XX}$, y entre las consecuencias de la disolución de límites, esencial de dicho recurso, se encuentran lo que Nelson Vieira denomina como el cuestionamiento de la autoridad [the question of 
CATEDRAL TOMADA: Revista de crítica literaria latinoamericana / Journal of Latin American Literary Criticism La iluminación de Macabea: el frac aso del narrador en La hora de la estrel la, de Clarice Lispector.

authority], es decir, la imposibilidad de confiar en un discurso completamente estable, plano y concreto que no deje ninguna incertidumbre sobre lo escrito, un rasgo que también ha sido usado para declarar el surgimiento de conceptos como la anti novela. (Vieira 586)

En efecto, términos como anti novela, o anti estilo, constituyen otros modos de clasificación con los cuales se suelen encasillar la empresa literaria llevada a cabo por Clarice Lispector o por algunos de sus contemporáneos brasileños. En las denominaciones de esta clase se engloban muchos de los rasgos que se posicionan en contra de la ortodoxia literaria; piénsense, por ejemplo, en mecanismo como la auto-ficción y las novelas históricas, en donde al espacio de la ficción le resulta imposible mantenerse intacto ante la intromisión de entidades que, aunque son igualmente discursivas, poseen una fundamento esencialmente distinto. Lo anterior permite afirmar que, en el fondo, el cuestionamiento de una autoridad no solo implica un rebajamiento de los roles narrativos, sino también el entendimiento de las novelas como imaginarios formados por piezas de distinta índole, las cuales, de entrada, podrían ser tildadas de anómalas o deformes.

No conviene detenerse aquí en los criterios que deben tomarse o no en cuenta para establecer una definición sobre el carácter novelístico de La hora de la estrella. En general, cualquier intensión por delimitar la estética recreada por la autora incurriría en diversas dificultades que ameritan un análisis separado en cuanto a los géneros literarios. Interesa, por el contrario, echar un vistazo al texto como una búsqueda, es decir, al modo en el cual este evade gran parte de los moldes bajo los cuales la ficción suele ser escrita, al tiempo que cuestiona y desestabiliza sus propios bordes, el ordenamiento de los elementos que lo componen y, particularmente, las voces que dentro de él pueden encontrarse.

En la narrativa de Clarice Lispector se aprecian algunas tendencias que problematizan la preponderancia de marcos totalmente estáticos o uniformes bajo los cuales escribir y narrar una historia. Si se observa a La hora de la estrella como el producto final de una madurez literaria gestada a lo largo de las décadas, el contenido del texto también se suma a los aspectos mencionados sobre la 
metaficción, las lecturas que sugieren la crítica de alguna instancia y la reivindicación de seres o formas de pensamiento alternas.

La caracterización de los personajes mismos parece seguir esta línea de forma muy clara. Inicialmente, es posible hacer algunas observaciones generales, la novela cuenta con nueve personajes en total: Rodrigo S.M., Macabea, Gloria, Olímpico de Jesús, las cuatro Marías y Madame Carlota. Siguiendo lo argumentado por Llanos, se parte de supuesto de que Rodrigo también constituye uno de estos personajes en tanto que es un narrador inventado para "crear" la historia y conformar el primer plano de lo que se está contando. Macabea y el resto de grupo vendrían a formar el segundo nivel de la narración, y en este punto es posible observar cómo Rodrigo construye tanto la historia de Macabea como una reflexión acerca de la actividad que está haciendo, es decir, que utiliza la escritura de forma recursiva:

Esta claro que como todo escritor, estoy tratando de usar términos suculentos: conozco adjetivos esplendorosos, camosos sustantivos y verbos tan elegantes que atraviesan agudos en el aire en busca de acción, ya que la palabra es acción, ¿o no están de acuerdo? (Lispector 14)

Como se puede observar, el narrador de la novela se jacta de conocer el oficio de la escritura, no solo por lo que cuenta, sino además por el saber estilístico que, a manera de argumento, justifica su posición en la historia. En el fragmento citado, la palabra y la acción son enlazadas mediante una suerte de analogía: la palabra-acción materializa una sola unidad en función de la cual los elementos del discurso novelesco son enunciados. Así, Rodrigo utiliza el lenguaje de manera redundante para legitimar el lugar que le ha sido dado, al tiempo que subordina y, por qué no, desestima, al mejor estilo de un dios, el rol desempeñado por los otros personajes. 
CATEDRAL TOMADA: Revista de crítica literaria latinoamericana / Journal of Latin American Literary Criticism La iluminación de Macabea: el frac aso del narrador en La hora de la estrel la, de Clarice Lispector.

Resultaría igualmente llamativo asumir lo anterior como un guiño o una alegoría a la concepción bíblica de la creación del universo. Tomando como punto de partida la opinión de Rodrigo sobre lo que hace y el poder que tiene la palabra como disparador de una cadena de acontecimientos, es posible ver lo cercana que resulta esta impresión a la idea del verbo-carne presente en el pensamiento cristiano y en la tradición occidental en general: la imagen de un ser-hombre primordial que ordena el caos previo a cualquier tipo de existencia.

Al respecto, María José Somerlate-Barbosa justifica la intromisión de Rodrigo en el relato bajo la premisa de que, para la tradición literaria, la presencia de un narrador masculino representa una base más inteligible y menos emocional con la cual dar fe de lo acontecido:

He [Rodrigo] assumes that because he is an important character, as well as the self-conscious male narrator, he can win and bridle the opinion of the public. Rodrigo asserts his generative power through his blind confidence that his gender will guarantee him the position of a stronger storyteller. (Somerlate-Barbosa 117)

Efectivamente, Rodrigo S.M. se asume como quien hará el relato, pero no cuenta directamente la historia de Macabea desde el principio, ya que, en cambio, se toma la tarea de convencerse a sí mismo [y a los lectores] de que posee el arsenal necesario para contar, ordenar y conocer los pormenores de una vida que no desea retratar. De igual modo, la acción de narrar la historia se ve pospuesta una y otra vez ante el tormento que supone escribir sobre Macabea, lo cual se irá develando a medida que el narrador avanza entre las circunstancias en las que creció y vivió la nordestina.

En este sentido, la personalidad de la voz narradora se encuentra claramente alejada de un ser completamente dominante, por el contrario, el personaje parece sufrir constantes cuadros de procrastinación que lo hacen ocupar su interés en 
otros pensamientos que no involucren su deseo con la memoria de Macabea. En realidad, la personalidad de Rodrigo en esta parte de la historia parece querer parodiarse a sí misma, no solo mediante la pena que implica el deber de escribir, si no por medio de las intromisiones/acotaciones ya mencionadas, las cuales fragmentan el ritmo de la historia y le muestran al lector la construcción de la novela desde otro punto de vista, tal y como sucedería con los escenógrafos y los tramoyeros en una puesta en escena.

Además, es necesario decir que las intenciones de Rodrigo nunca pasan de ser eso; realmente, el narrador no parece aceptar de modo enfático su tarea en ninguna parte de la novela pues, en cambio, muchas de sus propias reflexiones terminan convirtiéndose en quejas o excusas para evadir su condición autoritaria:

Va a ser difícil escribir esta historia. A pesar de no tener nada que ver con la muchacha, tendré que escribirme todo a través de ella por entre mis asombros. Los hechos son sonoros pero entre los hechos hay un susurro. Es el susurro lo que me impresiona. (Lispector 20)

La aseveración de Rodrigo propone, en primer lugar, una separación de su conciencia respecto de la mente de la protagonista de la novela. Si en principio el lector puede pensar que Rodrigo conoce a Macabea no porque la ha visto sino porque es una parte de ella, esta afirmación por parte del narrador coloca a ambos personajes en espacios delimitados y separados entre sí. En segundo lugar, Rodrigo sabe que para poder llevar a fin su empresa, debe dejarse permear por la mentalidad de la nordestina [escribir a través de ella], un rasgo que no solo cuestiona el poderío natural del narrador, sino que también lo humaniza y lo coloca en un nivel similar al del resto de los personajes, ya no solo porque sea un ser igualmente ideado, sino porque acepta el influjo que inminentemente recibirá del exterior, un sesgo o una fragmentación que dificultará en gran medida su plan de construir la historia a partir de una mirada completa, racional y objetiva. 
CATEDRAL TOMADA: Revista de crítica literaria latinoamericana / Journal of Latin American Literary Criticism La iluminación de Macabea: el frac aso del narrador en La hora de la estrel la, de Clarice Lispector.

Se muestra, entonces, cómo la escritura de Rodrigo S.M. se concibe como un intento, un ejercicio que no se halla completamente asentado ni en su personalidad ni en el método que utiliza para realizar la diégesis de relato. Incluso cuando se toma el trabajo de enfocarse en su personaje y hablar de lo que la rodea, sus reflexiones personales, marcadas en la novela con paréntesis, se incrustan en medio de la historia incontables veces y le recuerdan al lector que lo que está leyendo es producto de la imaginación de alguien más.

El narrador es, de esta forma, despojado parcialmente de la confiabilidad respecto a los hechos que ha testimoniado, lo cual se da por medios muy similares a los planteados por Vieira sobre la desestabilización de la jerarquía autoritaria dentro del texto literario frente a las fuerzas que surgen desde otros lugares que anteriormente solo eran hablados por el autor/narrador. Y sin embargo, el conocimiento de Rodrigo acerca de lo que ha llevado a la nordestina a la marginalidad permite afirmar que, después de todo, su figura, sí, puede estar en decadencia en relación con su deber de narrar certeramente, pero no se halla del todo deconstruida, ya que sigue razonando, disponiendo las circunstancias y las acciones de los otros de tal modo que estas puedan ser leídas.

Lo anterior representa la primera parte de una lectura cuyo propósito es entender al narrador de La hora de la estrella como un ser que, en vista de su rol dentro de la novela, es capaz de formular juicios autónomos mientras va trazando la ruta del texto que escribe. Rodrigo S.M. vuelve una y otra vez sobre sus pasos para mostrarle al lector dos cosas que resultan contradictorias: la jerarquía del relato, en donde él vendría a ocupar la posición más alta y objetiva, y la tortura que dicha condición representa para él. La metaficción no es, ciertamente, un aspecto del todo inexplorado en los textos de Clarice Lispector, no obstante, $L a$ hora de la estrella parece llevar al límite esta visión de un ordenador defectuoso o inútil mediante una acontecimiento igualmente extremo: la muerte/asesinato de Rodrigo al final de la novela. Pero ¿Por qué muere Rodrigo? 


\section{Oscilación}

En una buena parte de las reflexiones desarrolladas por el filósofo francés Henri Bergson, es posible rastrear algunas líneas generales alrededor de las cuales se sustentan sus argumentos acerca de los límites de la consciencia humana. Probablemente influenciado por las ideas psicológicas de la época, Bergson creó un abordaje que, muy al contrario de las visiones estructuradas a partir del positivismo durante el siglo XIX, situaba el pensamiento emocional en un lugar evidentemente alejado de la perspectiva que lo descalificaba en virtud de la ciencia y del racionalismo.

El misticismo, la espiritualidad y las subjetividades eran elementos que, dada su naturaleza, se resistían en su tratamiento a la interpretación hecha por disciplinas como las ciencias exactas o los fundamentos objetivos. Más significativo resulta aún la perspectiva de lo mítico usada por otros autores como Roberto Sánchez-Benítez, quien incluye en dicha noción, además de los aspectos mencionados, otras características como la profesión de la fe, el establecimiento de una moral y las manifestaciones individuales llevadas a cabo en determinadas circunstancias. (3)

La trascendencia de las discusiones fundamentadas por Bergson radica en la existencia de una oscilación entre los dos frentes que otros de sus contemporáneos defendían de manera absoluta, a saber, la presencia de una verdad completamente racional, y la práctica de creencias arcaicas o emocionales, ambos con el ser humano y la sociedad como principales centros de conflicto. De este modo, se hace una referencia directa a la pugna tradicionalmente sucedida entre dos vertientes que, estudiadas de cerca, constituyen un modelo de indagación comprometido con un entendimiento de las relaciones de tensión o dialogo que entre la razón y la emoción pueden llegar a establecerse, al tiempo que reivindican la presencia de un pensamiento no inteligible ni objetivo en las personas.

Más recientemente, algunos autores han contextualizado lo expuesto por Bergson dentro de discusiones que problematizan el carácter que la religión y la 
CATEDRAL TOMADA: Revista de crítica literaria latinoamericana / Journal of Latin American Literary Criticism La iluminación de Macabea: el frac aso del narrador en La hora de la estrella, de Clarice Lispector.

moral tiene en las mentalidades colectivas. Autores como Michael Vaughan retoman las posiciones establecidas por el filósofo francés acerca de la naturaleza de la realidad, vista como una mezcla de la pulsión inerte y explosiva, dos nociones bajo los cuales se da una relectura de la evolución humana. La realidad se da, por tanto, de la unión de estos dos componentes, y resulta en lo que Vaughan denomina la cosa viviente [living matter]. Asimismo, el concepto de la organización de los sujetos se conforma a su vez en la esfera individual y social, cuyos puntos culminantes implican la separación de estos dos polos, los cuales son representados en la organización de los insectos y la de los humanos, en donde los humanos se diferencian de los insectos, ante todo, por su capacidad de razonamiento. (Vaughan 17)

En este sentido, es posible ver cómo la individualidad humana, debido a la potestad de las personas llevar a cabo juicios propios, no se encuentra subordinada a la organización social-colectiva, tal y como sucede en el ejemplo de los insectos ilustrado por el autor. Así, la existencia de una organización social no influye directa o exclusivamente en la constitución individual del ser humano, quien, a diferencia de las hormigas o de los gusanos, tiene la capacidad de formular y fabular razonamientos a partir del libre albedrío. La religión y los esquemas morales se llevan a cabo precisamente en este espacio personal, en donde la armonía supone una dosis equilibrada de principios opuestos:

Too much creativity, too much freedom, and the identity of the organization within its environment is threatened; it may unravel. Too much necessity, too much structure, and an organization may close upon itself and practically cease to grow and change. (Vaughan 18)

Como se puede observar, dicho punto de vista justifica la presencia de un esquema de subjetividades que, en no pocas ocasiones, los argumentos positivistas critican o desechan por considerarlo un discurso carente de fundamentos sólidos (objetivos) que lo defienda. Sin llegar a forzar el texto de 
Clarice Lispector, es posible apreciar que la explicación citada en torno a la necesidad de un equilibrio entre las nociones de organización y libertad se ilustra en la novela, en este caso, mediante la existencia de un narrador [estructurado] que va descubriendo sus propios límites y las frustraciones que estos implican, y la presencia de personajes [creados] con juicios de valor que escapan del criterio del narrador, cuya principal deficiencia se muestra en la imposibilidad de contener la libertad del personaje central de Macabea.

Un repaso por estas afirmaciones a la luz del discurso literario, dentro de la narrativa escrita durante el siglo XX y, en este caso en La hora de la estrella, arroja algunas cuestiones igualmente inquietantes. Los personajes del relato de Lispector, aun sin ser numerosos, muestran cómo, después de todo, no resulta pretensioso afirmar que ni la aparición de nuevas formas de reflexión, ni el perfeccionamiento de mecanicismos para medir la conducta de las personas han conseguido eliminar por completo la oposición entre la razón y la creencia, al menos no hasta el momento.

La reflexión de Vaughan, además, brinda la oportunidad de retomar lo explicado al inicio acerca del vaivén presente en la novela entre la forma de pensamiento de Rodrigo S.M., quien intenta dejar su impronta sobre lo que está haciendo [escribir], y otra forma que resulta ser demasiado libre, como sucede con Macabea, o demasiado moral, como en el resto de los personajes. Ambos polos, tal y como lo explica el autor en relación con las formulaciones citadas, se colocan sobre el texto y se refuerzan sus mentalidades en una buena parte de la historia. La caracterización de los personajes podría facilitar la comprensión de la propuesta de Henri Bergson y la pertinencia de sus hipótesis en este análisis.

La figura más memorable del texto es, además de Macabea, la de Olímpico de Jesús, el obrero de metalurgia que se atraviesa en la vida de Macabea durante el desarrollo de la historia. Olímpico se presenta ante los lectores como el personaje que reúne las cualidades de masculinidad y fuerza que se esperan del hombre arquetípico, es, por cierto, el único personaje masculino además del narrador. De igual modo, como si su nombre lo esencializara desde un primer 
CATEDRAL TOMADA: Revista de crítica literaria latinoamericana / Journal of Latin American Literary Criticism La iluminación de Macabea: el frac aso del narrador en La hora de la estrella, de Clarice Lispector.

momento, la personalidad de Olímpico de Jesús se rige bajo la regla de los preceptos heredados directamente de la religión, tal y como se ve en las increpaciones que hace acerca del descubrimiento del mundo por parte de Macabea: “ ¿Te parece que esas son palabras para que diga una chica virgen? ¿Y para qué te sirve saber tanto? El Mangue está lleno de jovencitas que hicieron demasiadas preguntas". (Lispector 40)

Olímpico de Jesús se erige así como la primera fuerza dentro de los personajes de la historia que, en razón de su masculinidad, es capaz de pasar por encima de la inocencia de Macabea, al punto en que juzga su pensamiento sin tomar en cuenta que su propia vida no cumple a cabalidad con los preceptos que él mismo profiere. No obstante, cabe la oportunidad de sugerir que la justificación de su actitud prejuiciosa y oportunista reside en su condición de hombre, ya que, si bien el resto de los personajes intenta cambiar o criticar la vida de la nordestina, ninguna llega a hacerlo de forma tan cruel. Dicha condición lo sitúa de forma estereotipada en un lugar superior, olímpico, y le da la capacidad de moverse a conveniencia tanto consigo mismo como con lo demás, lo cual explica su insípido noviazgo con Macabea y el modo en el cual termina reemplazándola por Gloria, tal y como lo haría con cualquier otro objeto.

Prácticamente todas las intervenciones hechas por Olímpico de Jesús se encuentran enmarcadas en observaciones como la anterior. De acuerdo con esto, el personaje es un ser que detiene a Macabea en sus intenciones por conocer un mundo por el que hasta ahora solo se ha movido impulsivamente. A Olímpico no le interesa conocer ni entender el significado profundo o la razón de ser de las cosas: “¿Pero vos no te diste cuenta? ¿No pensaste que todo lo que preguntás no tiene respuesta?". (Lispector 36) Su personalidad no busca justificar la existencia de lo que le rodea pues, por el contrario, su vida se desarrolla a partir de una aceptación total de lo que piensa y observa.

$\mathrm{Si}$ se retoma nuevamente la lectura sugerida por Llanos sobre las implicaciones sociales presentes en La hora de la estrella, el personaje de Olímpico de Jesús podría ser estudiado como otra forma de individuo que 
margina, pero ahora mediante la intolerancia y la no comprensión hacia Macabea. La personalidad de Olímpico encontraría una explicación en el hecho de que, si bien su origen no es opulento en lo absoluto, su estilo de vida halla viciado por el imaginario que los habitantes de la gran ciudad tienen acerca de las personas que habitan en el interior del territorio brasileño, por el consumismo y los intereses materiales que priman por sobre cualquier clase de cualidad humana.

Aunado a esto, es paradójico notar que la conciencia de Macabea, aunque inquieta e ignorante, es mucho más exhaustiva que la de Olímpico de Jesús, para quién los esquemas morales resultan mucho más fuertes que las dudas planteadas por la nordestina. Las referencias al Mangue [un término que en la voz de Olímpico parece connotar el purgatorio de la religión cristiana] así como la estigmatización de quienes intentan comprender demasiado lo que les rodea, refuerzan la noción de Olímpico de Jesús como un hombre carente de profundidad emocional, lo cual, es lo que termina alejándolo de la protagonista.

Una referencia igualmente directa al pensamiento religioso, aunque menos explorada en la novela de Lispector, se halla en el grupo de compañeras de habitación de la protagonista, las cuatro mujeres llamadas María: María da Penha, María Aparecida, María José y María a secas. Si bien sus personalidades permanecen sin ningún detalle exhaustivo en el relato, es curioso notar que Macabea consigue descubrirse a sí misma solo cuando estas cuatro mujeres salen de su hogar y la dejan sola. No sería aventurado decir que, de haberse explayado más en sus descripciones, la vida de estas cuatro mujeres con seguridad habría sido muy parecida a la de Olímpico de Jesús o incluso a la de Gloria.

Finalmente se tiene a Madame Carlota, el último personaje con el que Macabea se topa en su travesía. La médium es una mujer cuya vida se encuentra constituida por dos principios fundamentales: la profesión de la fe y el conocimiento del azar visto como un regalo venido de la divinidad. Ambos polos enlazan el espíritu y la personalidad de la médium de una forma particular, pues en ella se funden dos formas de creer que, en principio, resultarían opuestas o inaceptables: el seguimiento estricto de la religión cristiana y la práctica rituales 
CATEDRAL TOMADA: Revista de crítica literaria latinoamericana / Journal of Latin American Literary Criticism La iluminación de Macabea: el frac aso del narrador en La hora de la estrel la, de Clarice Lispector.

mágicos o esotéricos. Dicha contradicción en realidad carece de importancia no solo respecto a la médium, sino también con respecto al resto de los personajes mencionados, ya que todos, de un modo u otro, ocupan papeles que lo sitúan en un espacio espiritual o moral alejado de conocimiento concreto que Rodrigo intenta describir en la historia en tanto narrador omnisciente. Y es aquí donde el lector puede descubrir dos cosas: la tensión entre la voz del narrador-personaje de la novela y los personajes de la historia, y la no pertenencia de Macabea a ninguno de estos dos márgenes.

Incluso es posible sostener que La hora de la estrella se escribe porque la protagonista de la historia no pertenece al universo que se narra. El relato de Macabea es la historia de su propia búsqueda, del descubrimiento casi infantil con el que el narrador la coloca frente a la ciudad. A Rodrigo S.M. le es encomendada la función de entender y enunciar la historia, y eso hace que quien vuelva la mirada hacia Macabea descubra que, efectivamente, este personaje se mueve en algún lugar entre el salvajismo y la inconsciencia.

Macabea no solo desconoce el funcionamiento de sus procesos mentales, que solo son objeto de interés para el narrador, sino que además carece de esquemas morales o sociales bajo los cuales manejar su propia vida: "Ella pensaba que las personas están obligadas a ser felices. Entonces lo era. Antes de nacer ¿Ella era una idea? ¿Antes de nacer ella estaba muerta?” (Lispector 22) La ignorancia de Macabea puede incluso interpretarse bajo un sinfín de otros términos: torpeza, candidez, estoicismo, la presencia de un estado del ser tan inicial que no admite ninguno de los prejuicios con los cuales el mundo que la rodea ha sido esquematizado.

La misma existencia de Macabea, en este punto de la historia, ni siquiera puede denominarse vida en tanto que el personaje desconoce por completo la finitud de su persona. Si antes de nacer Macabea estaba o no muerta, es algo que a ella le resulta por demás irrelevante, pues, más allá de estos dos polos biológicos y temporales, la nordestina solo alcanza a entenderse a sí misma como una permanencia constante en un espacio que no [la] comprende. De esta forma, se 
puede ver cómo la imagen de Macabea es, ante todo, una suerte de vacío que ha sido puesto en el mundo sin un objetivo claro, casi como si se la trasladara en el tiempo hacia un lugar al cual no pertenece. Macabea no habla, es hablada por quienes la conocen: el narrador, en su pensamiento, y los personajes, en sus acciones y palabras, y este aspecto es precisamente el que permite ver cómo los dos bandos se disputan el destino de la muchacha a lo largo del relato.

Así, se aprecian dos estados en medio de los cuales la nordestina es manipulada. Por un lado, Rodrigo S.M., el escritor que lamenta ser el ordenador de la totalidad de la historia y de la mente de Macabea; por el otro, los personajes que la rodean y que representan un saber racionalmente ilógico pero completamente aceptado en su entorno. Se establece de esta forma una tríada en disputa [Rodrigo-Macabea-Entorno, o: conocer-ignorar-conocer], en donde Macabea viene a ser una especie de mentalidad primordial, ajena a ambos polos.

La novela discurre con episodios que resumen las diversas iluminaciones inducidas a Macabea, para finalmente colocarla de frente con un descubrimiento que resulta serle demasiado abrumador. Cuando a ella le es develado el poder del azar y el conocimiento de Jesús por parte de la médium, su [in]consciencia primaria parece derrumbarse sobre sí misma en un acontecimiento muy cercano a la epifanía, cuyo movimiento final acaba con la vida de la protagonista y arrastra tras de sí al narrador, quien hasta entonces parecía ser el único que gozaba de la potestad sobre la historia: "Macabea me mató. Ella estaba finalmente libre de sí y de nosotros. No se asusten, morir es un instante, pasa en seguida, lo sé porque acabo de morir con la muchacha". (Lispector 59)

La culminación de la búsqueda emprendida por Macabea termina por convertirla en una asesina, la que da muerte definitiva a la autoridad de la novela. A pesar de esto, incluso tratándose del desenlace, resulta difícil señalar a la nordestina como la culpable del destino del narrador. La vida de Macabea parece llegar a su fin sin que ella sea realmente consciente de lo que le ha sucedido, sin que el personaje pueda siquiera anticipar lo que va a pasar después de su visita a la casa de la Madame. De hecho, es posible sostener que Macabea descubre su 
condición de ser solo después de su muerte, cuando por fin consigue apropiarse del pensamiento de Rodrigo S.M. y llevárselo consigo. Los esfuerzos del narrador terminan siendo inútiles pues la liberación de la nordestina, de sí misma y del mundo, solo puede darse con el final de su propia existencia.

Este último punto es el que permite dar respuesta a la pregunta del primer apartado: Rodrigo muere porque su estrategia de conocimiento [ordenar, escribir] no puede sostenerse ante el saber que Macabea recibe desde la otra orilla. La revelación dada a la protagonista, curiosamente, no viene de quien se tomó la tarea de contar su historia de forma objetiva, lo cual podría interpretarse como la ruina del narrador tal y como se conoce, cuya derrota, al mismo tiempo, viene a representar la ascensión y la victoria del pensamiento de los personajes que él mismo "creó" y narró, subvirtiendo así la jerarquía narrativa de la novela.

Es así como la metaficción en La hora de la estrella se ve trastocada, precisamente, porque la narración en su totalidad, representada en la escritura de Rodrigo S.M., fracasa ante la iluminación final de la protagonista. Una iluminación que, en última instancia, no le fue mostrada a Macabea en ningún momento por el saber ordenado del narrador, acaso porque pertenece a un ámbito antagónico, alejada de las experiencias probables e incluso del lenguaje que él quiso utiliza para dar fe de ellas. 
CATEDRAL TOMADA: Revista literaria latinoamericana / Journal of Latin American Literary Criticism Kevin Andrés Pérez Méndez

\section{Bibliografía}

Helena, Lucia. "A Problematização da Narrativa em Clarice Lispector". Hispania 75 (1992): 1164-1173.

Lispector, Clarice. La hora de la estrella. Buenos Aires: El Corregidor, 2011.

Llanos, Bernardita. "Clarice Lispector/Suzana Amaral. A estrela nordestina o la fatalidad del género en el margen carioca". Revista de Crítica Literaria Latinoamericana 37 (2011): 271-288.

Sánchez-Benítez, Roberto. "Pensar la religión con Bergson". Revista Mexicana de Sociología 61 (1999): 3-17.

Somerlate-Barbosa, María José. "«A hora da estrela» and «Um sopro de vida»: Parodies of Narrative Power”. Chasqui 20 (1991): 116-121.

Vaughan, Michael. 'Henri Bergson's 'Creative Evolution””. SubStance 36 (2007): $7-24$.

Vieira, Nelson H. "Metafiction and the Question of Authority in the Postmodern Novel from Brazil”. Hispania 74 (1991): 584-593. 